\title{
Diálogo sobre os dois principais sistemas do mundo: o "senso comum" e o "senso científico"
}

\author{
de Raquel Gonçalves, Terramar, Lisboa, 1997.
}

\begin{abstract}
1- O livro Diálogo sobre os dois principais sistemas do mundo: o "senso comum" e o "senso científico" da autoria de Raquel Gonçalves (Terramar, 1997) proporcionou-me uma primeira leitura agradável pela originalidade que revela na intenção, pela eloquência da escrita, pela lírica que transpira dele (e que não está ao alcance fácil da escrita de quem tem a ciência como formação e como actividade profissional). A passagem da situação de leitor à de comentador obrigou-me, naturalmente, a uma leitura mais analítica da obra, na mira de uma visão mais profunda e clarificadora da sua estrutura, da sua forma, da sua função e das respectivas interrelações. Tal leitura mais atenta e questionadora suscitou-me, como é natural, um conjunto de questões que tentarei no que se segue enunciar. Não estou habilitado para fazer crítica literária, não sendo pois essa a minha intenção. Também não atribuo aos comentários que se seguem o valor de verdades absolutas ou de juízos definitivos. Antes gostaria que eles fossem encarados como um conjunto de opiniōes, algumas de natureza muito pessoal, susceptíveis de contribuir para uma apreciação dialogante da obra em causa.
\end{abstract}

2 - A questão mais genérica que se coloca face a este livro é a de saber de que tipo de obra se trata. Acusar-meão talvez de metodologia redutora, por perseguir intenções classificatórias, por tentar encontrar rótulos que cataloguem de uma vez por todas a obra numa determinada prateleira. Eu diria antes tratar-se de uma metodologia útil e necessária para procurar abrir janelas, ângulos de visão através dos quais se torne possivel olhar compreensivamente para o texto em causa. Tratar-se-á de uma simples ficção literária? De um exercício de epistemologia? De um ensaio de filosofia das ciências? De um texto de divulgação científica? O texto em consideração é um pouco de tudo isto, e esta característica, que para muitos constituirá porventura a fonte da sua originalidade, é para mim a origem das suas fragilidades. Isto porque, seja qual for o ângulo de visão, a perspectiva através da qual seja encarado, ele revela algumas fraquezas ou insuficiências.

3 - Há sem dúvida neste texto uma componente substancial de divulgação científica, estando a intenção divulgadora explicitada no prólogo e penetrando ela toda a estrutura do texto no qual D. Quixote é o divulgador, Sancho o grande público, cabendo a Simplício um papel de moderador, de "pyvot", por vezes de elemento clarificador do diálogo. É de sublinhar aqui o cuidado da autora em esboçar os seus personagens de uma forma contraditória, evitando o simplismo e o monolitismo. D. Quixote ora discorre no quadro de um cientismo dogmático ("Longe vai o tempo do conhecimento generalista. A ciência actual vive de especialistas e de especialidades" ou “Hoje , em ciência, já não há tempo para amadorismo, que é contrário de profissionalismo, nem demoras nas pesquisas, nem inutilidades no conhecimento adquirido"), ora se apresenta como defensor da liberdade e da dialéctica do conhecimento científico. Simplício ora surge como um espírito aristotélico limitado, ora se revela deslumbrado pelas descobertas e métodos da ciência moderna.

4 - Por divulgação científica entendese uma actividade de explicação e difusão dos conhecimentos, da cultura e do pensamento científico e técnico, que tenha lugar fora do contexto das instituiçōes de ensino, que não tenha por objectivo formar especialistas ou aperfeiçoá-los na sua especialidade, mas antes que tenha por alvo fundamental um público vasto. Nesta sua faceta de divulgação científica, o texto em apreciação fala de muita coisa, em minha opinião de coisas demais. Fala do Sol e da Terra, do movimento dos astros, dos números (negativos, primos, imaginários, irracionais, ...). do infinitamente grande e do pequeno, da radiação, da matéria e do vazio desta, de elementos e compostos, de fractais, dos fulerenos, do ozono e do seu buraco, de poluição, de genética e de clonagem, etc.... Não admira que tal inflaç̧ão temática em tão curto espaço de escrita tenha como inevitável consequência alguma superficialidade da divulgação. Digo isto com perfeita consciência de não estar-

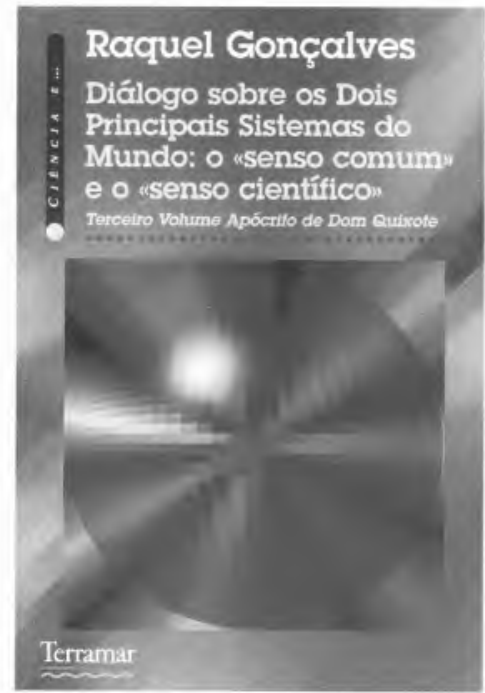

mos aqui a falar de um ensaio de divulgação científica, mas antes de um texto literário que apresenta diversas facetas, uma das quais a da divulgação científica.

5 - Mergulhando um pouco em aspectos de maior particularidade, algumas observações se impõem, ao longo do texto, relativamente a aspectos pedagógicos e ao rigor dos conceitos explanados. Esta pequena nota não pretende ser exaustiva no enunciado e análise destes pormenores e por isso limitome a dar um exemplo para ilustrar o que me vai no espírito. A frase: "Um vidro não é um sólido, nem é liso, nem é homogéneo", é para mim um espaço vazio de significado, tanto do ponto de vista científico como do ponto de vista didáctico. Um vidro não é um sólido? Eu pensaria que sim, amorfo mas sólido. Será a ausência de lisura uma propriedade fundamental da superficie de um vidro? Eu diria que não o será, nem de um vidro nem de qualquer outro material, dependendo a lisura de uma superfície da forma como for preparada ou dos tratamentos a que fôr submetida. Será um vidro essencialmente heterogéneo? Não me parece que assim seja, não sendo a sua eventual heterogeneidade característica distintiva relativamente a outros materiais diferentes.

6 - Ainda no capítulo das particularidades, a história de os vidros dos vitrais das catedrais da Idade Média serem mais grossos na base, mais finos no 
topo, está mal contada quando se diz que tal acontece devido à fluência do vidro, induzida pelo campo gravítico, ao longo dos séculos. É certo que esta história se encontra mal contada em muitos textos, mas tal não justifica que o erro se eternize. No tempo em que se construíam catedrais, e por razões tecnológicas fáceis de compreender, o vidro que se produzia para os vitrais não tinha uma espessura constante. Os artesãos que faziam os vitrais optavam. conscientemente, por colocar a parte mais espessa dos vidros para baixo por entenderem que tal conferia aos vitrais uma maior solidez, resistência e estabilidade. A história assim contada é mais plausível do ponto de vista científico. Isto porque medidas experimentais de fluência, levadas a cabo com vidros submetidos a tensões milhares de vezes superiores aquelas geradas pelo campo gravítico, mostram ser aquela perfeitamente desprezável (ver por exemplo C. A. Angell, Journal of Research of the National Institute of Standards and Technology, vol. 102, pgs 171-185 (1997)). Quer isto dizer que os movimentos moleculares que originam a fluência no vidro dos vitrais têm tempos característicos tão longos que muitos milénios seriam insuficientes para produzir o efeito observado.

7 - A par da componente de divulgação científica, existe no texto em consideração uma forte componente a que se poderia chamar de filosofia do conhecimento, na qual se disserta extensamente sobre o estatuto filosófico do conhecimento científico e sobre o fosso existente entre a cultura literária e artística por um lado, e a cultura científica e técnica por outro. O que sobre este assunto é dito é sobejamente conhecido, tanto no conteúdo como na forma, e não seria aliás de exigir da autora, dada a natureza da obra, qualquer intenção ou pretensão inovadora nesta matéria. Existem ao longo da obra, e em torno desta temática, momentos muito interessantes de invenção romanesca, de construção literária. Gostaria apenas, e a este respeito, de exprimir um sentimento pessoal que se formou através da minha leitura da obra. É que não é o discurso divulgador que sugere, implica ou impõe o discurso filosófico. Trata-se pelo contrário de dois discursos disjuntos, que se desenvolvem numa relação que é mais de justaposição do que de articulação, conferindo à estrutura do texto um carácter de mistura heterogénea ou de amálgama de discursos. Creio que a obra ganharia em força cultural, em solidez intelectual, e até em comunicabilidade para o grande público, se tivesse sido possível dar uma maior mąterialidade à articulação entre as duas perspectivas, entre os dois discursos.

8 - O Diálogo Sobre os Dois Principais Sistemas do Mundo transforma-se a certa altura numa bandeira ou numa apologia da chamada Transdisciplinaridade. É o culminar do diálogo entre os três personagens (D. Quixote, Sancho e Simplício) que, depois de muito penarem em desencontros e desentendimentos, finalmente encontram a calma do consenso graças às virtudes miraculosas da dita transdisciplinaridade. Há muito que sociólogos, filósofos, homens de ciência pensam e escrevem sobre o estatuto da ciência no mundo contemporâneo, sobre os modos de produção do conhecimento científico, sobre a relação entre a ciência e o poder, sobre a relação entre a ciência e a filosofia, sobre a unidade (perdida?) do conhecimento. Muitos destes problemas têm conotações políticas óbvias. Parece-me ingénuo afirmar, cito, que razão não há para duvidar da excelência dos seus (da Ciência e da Tecnologia) objectivos em mãos sábias e honestas. A concepção subjacente é a de que a ciência é intrinsecamente boa, havendo no entanto espíritos malévolos, mal intencionados, que lhe trazem mácula fazendo dela uma má utilização. Desta forma se transforma em problema moral um problema que é, fundamentalmente, um problema político. A ciência em si é uma abstracção. Do ponto de vista sociológico aquilo que tem realidade é um sistema no qual a ciência se produz e se aplica, conjunto de instituições financiadas pelo poder político, dotadas de uma estrutura hierárquica ela própria concebida e reproduzida pelo poder político, funcionando de acordo com regras e rituais próprios. Não me parece possível entender o papel da ciência no mundo de hoje sem uma análise do sistema científico no seu conjunto e nos seus diversos aspectos. A Transdisciplinaridade? Diz-se não ser ela uma nova disciplina (ela paira para além das diferentes disciplinas) mas antes uma atitude nova, um novo olhar vocacionado para ressuscitar ideais e saudosas utopias que ajudarão a fazer o Mundo melhor... Não chega! De boas intenções está o Mundo cheio... Acredito no valor da Utopia, mas não na Transdisciplinaridade. Muito já foi dito e escrito sobre as clivagens e separações geradas ou acentuadas pelo acelerado desenvolvimento científico e tecnológico deste século. Houve quem encontrasse na filosofia contemporânea a vocação de uma ciência das ciências com a missão de unificar o conhecimento, articular metodologias e arbitrar os excessos da especialização. Não faltam análises, formulações e propostas. Mas não vejo que a transdisciplinaridade acrescente novidade ou riqueza ao que já existe. A Transdisciplinaridade será mais um conceito em moda, isto é uma nova mercadoria com boa cotação em certos mercados intelectuais restritos. Os transdisciplinares são os membros de uma nova pequena seita, felizmente pacífica. Mas não vejo nos transdisciplinares estofo crítico e filosófico para nos abrir novos caminhos para of futuro.

9 - Para finalizar, retomo o que dizia no início: a leitura deste livro é uma actividade lúdica agradável para leitores com formação científica muito diversificada. A obra é, pela sua natureza, exemplar raro no universo da nossa literatura e abre uma via promissora. $\mathrm{O}$ exercício intelectual através do qual a autora pôs de pé esta construção literária é um exercício original e fecundo. O Diálogo Sobre os Dois Principais Sistemas do Mundo já faz parte do nosso património literário e creio que terá aí influências frutificadoras.

Joaquim José Moura Ramos. Departamento de Engenharia Química, Instituto Superior Técnico 